\title{
Steady-state and Dynamic Study of One-Cycle Controlled three-phase Active Power Filter ${ }^{\dagger}$
}

\author{
Guozhu Chen ${ }^{\dagger \dagger}$ and Keyue M. Smedley \\ Department of Electrical Engineering and Computer Science \\ University of California Irvine, CA92697, USA
}

\begin{abstract}
One-Cycle Control Active Power Filter (OCC-APF) with vector operation is a promising method to cancel harmonics and correct power factor. It features simple circuit, high performance, and excellent stability. This paper studies the performances of both the steady-state and dynamics. The stability condition for three-phase OCC-APF is first derived. Some typical large signal perturbations and the tracking ability for the fast transient are investigated, which provides guidelines for the design the control circuit and the main circuit. All analysis and results were verified by simulation and experiments based on a three-phase $5 \mathrm{~kW}$ pre-industrial OCC-APF prototype.
\end{abstract}

Keywords- Active power filter (APF), Power quality, One cycle control (OCC), Harmonic suppression.

\section{INTRODUCTION}

Power electronic equipment is widely used in homes, industry, space, and military. Unfortunately these types of equipment impose nonlinear loads to the $\mathrm{AC}$ grid, which draw harmonic and/or reactive current in addition to active one from the AC grid and harm the power system and other equipment connected at the Point of Common Connection (PCC). As applications of power electronic equipment increasing, the problems related to harmonic pollution, low power factor, and low efficiency of the power system have become more serious.

In the past, passive power filters were used to attenuate the harmonics. These filters are usually very bulky. Moreover, the addition of a massive capacitance and inductance to the power system is a potential danger for causing resonance. In resent years, an alternative solution for harmonic suppression using active power filters (APF) has been reported by many researchers. Typically, an APF is connected in parallel to a nonlinear load and it generates anti-harmonics to cancel the one from the load. In most proposed approaches, the load current is sensed to calculate the harmonic contents, which is then used as the control reference for the APF, while the APF is usually controlled by using $\mathrm{p}-\mathrm{q}$ or $\mathrm{d}-\mathrm{q}$ method ${ }^{[8,9]}$, which results in a complex circuit, high cost, and low stability.

The One-Cycle Control (OCC) techniques ${ }^{[1]}$ established a large signal nonlinear PWM scheme that features a simple circuit, high performance, and universal applications. OCC has been successfully implemented in many branches of power electronics including DC/DC converters, amplifiers, $\mathrm{DC} / \mathrm{AC}$ inverters, $\mathrm{PFC}$ and $\mathrm{APF}$ in both single-phase and three-phase. ${ }^{[1] \sim 7]}$ The OCC controller usually uses an integrator with reset to force the controlled variables to meet with the control goal in each switching cycle. It has the advantages of fast response and high precision.

A three-phase vector operated OCC-APF was first reported in literature [4]. It achieved three-phase unity-power-factor and low total harmonic distortion (THD) without harmonic reference calculation. The control circuit is therefore very simple: one integrator with reset, along with a few linear and digital components. The OCC-APF features constant switching frequency (desirable for magnetic design) and vector operation (lower switching losses compared to PWM operation).

In order for a new concept to be industrially and commercially adopted, it is necessary to perform a rigid evaluation of circuit for possible practical scenarios and develop solid engineering design guidelines. This paper focuses on the study of the performance of both steady and dynamic states. All analysis and results are verified by the experiments based on a three-phase $5 \mathrm{~kW}$ pre-industrial OCC-APF prototype.

\section{REVIEW OF OCC-APF WITH VECTOR}

\section{OPERATION}

The OCC-APF shown in this paper is composed of a three-phase bridge as the main circuit and a One-Cycle Controller as shown in Fig. 1. The main circuit is a three-phase bridge voltage source inverter connected in parallel to the three-phase load. The DC voltage source $E$ is realized by a capacitor, which is feasible since the APF only processes reactive and harmonic power. The power line provides symmetric sinusoidal three-phase voltages $V_{\mathrm{a}}, V_{\mathrm{b}}, V_{\mathrm{c}}$ and currents $I_{\mathrm{a}}, I_{\mathrm{b}}, I_{\mathrm{c}}$ in the normal operation. The voltage source inverter contains three inductors $L_{\mathrm{a}}=L_{\mathrm{b}}=L_{\mathrm{c}}=L_{\mathrm{f}}$ and six switches $S_{i j}$ on the up-leg (when $j=p$ ) or the low-leg (when $j=n$ ) for phase $\mathrm{i}(\mathrm{i}=\mathrm{a}, \mathrm{b}, \mathrm{c})$ respectively. The two switches in each phase are operated in complementary. The converter is always

$\dagger \quad$ This project was supported by California Energy Commission under Grant \# 52100A/00-27.

$\dagger$ Guozhu Chen is in the faculty of EE College in Zhejiang University, China and he is visiting Dept. of EECS, University of California Irvine, USA as a postdoctoral researcher since Jan., 2002. 
in continuous conduction mode (CCM) due to the four-quadrant operation nature ${ }^{[4]}$.

The control circuit contains an OCC core, some vector operation logics, and a feedback loop, as shown in Fig.1 (b). The OCC core includes three adders, two comparators and an integrator with reset as well as two flip-flops; the vector operation logics contains a vector region selection circuit that divides a line cycle into six regions according to the power line voltage $V_{\mathrm{a}}$, a multiplex circuit that selects the vector current $I_{\mathrm{p}}, I_{\mathrm{n}}$ from the three phase current $\left(I_{\mathrm{a}}, I_{\mathrm{b}}, I_{\mathrm{c}}\right)$ and directs two drive signals to the right switches, and the feedback loop that regulates the DC bus voltage (slow loop) and feeds the One-Cycle Control fast loop. The DC bus voltage $E$ is regulated against a constant reference voltage $V_{\text {ref }}$ so that no real power flows into or out from the capacitor $\mathrm{C}$ during steady-state operation. The error signal passes a PI controller $A_{\mathrm{v}}(\mathrm{s})$ to form the modulation signal $V_{\mathrm{m}}$. The OCC

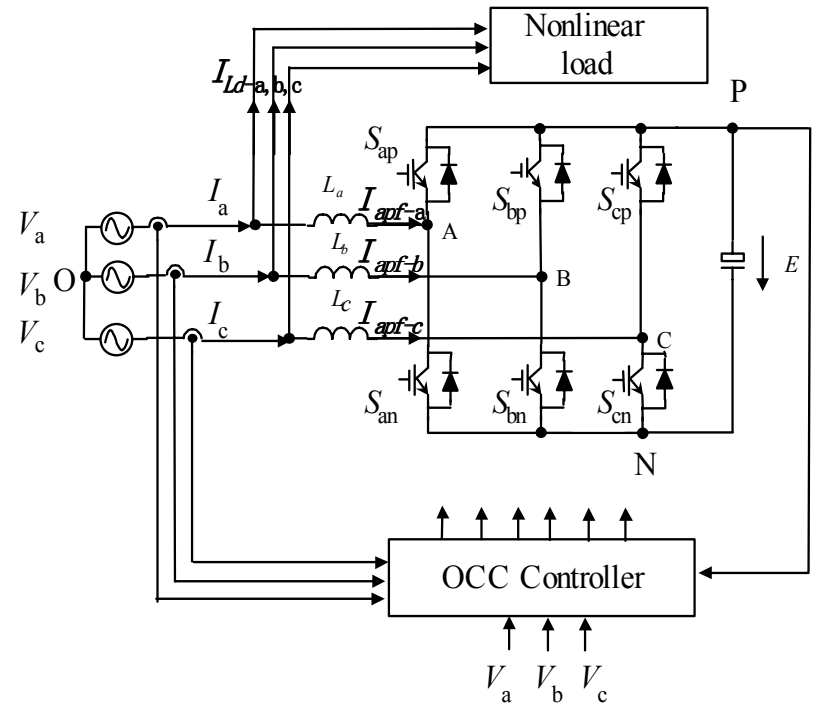

(a) Main circuit of the OCC APF

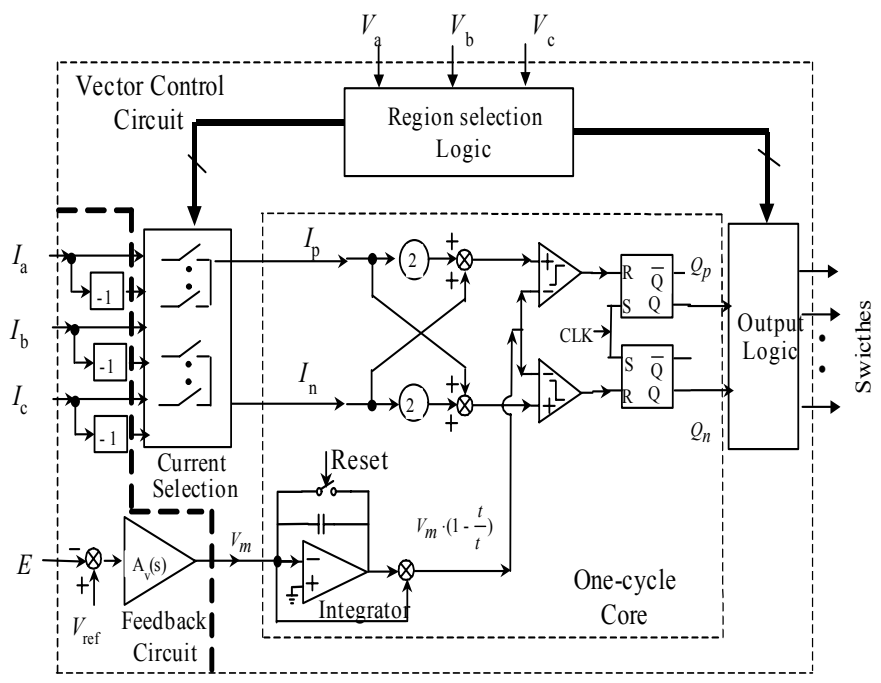

(b) OCC controller

Fig. 1. Circuits of the three-phase OCC APF with vector operation control core takes the modulation signal $V_{\mathrm{m}}$ together with the vector currents $I_{\mathrm{p}}, I_{\mathrm{n}}$ and to produce switch trigger signals $Q_{\mathrm{p}}$ and $Q_{\mathrm{n}}$ at the output of the Flip/Flops, whose status are (1:ON; 0:OFF). The duty ratios $d_{\mathrm{ij}}$ are the associate switch $\mathrm{S}_{\mathrm{ij}}$.

For vector operation, a line cycle is equally divided into six regions. Only the switches of two phases are controlled using the duty ratios given by the OCC core at each vector region while the switches in the remaining phase are kept ON or OFF during the whole selected region, which results in minimum switching losses. The vector turns to a new region in each $60^{\circ}$ of one line cycle. This mechanism is shown in Table I.

TABLE.I

Vector Operation Mechanism OF THE OCC APF*

\begin{tabular}{|c|c|c|c|c|c|c|c|}
\hline \multicolumn{2}{|c|}{ Region } & I & II & III & IV & V & VI \\
\hline \multicolumn{2}{|c|}{$\begin{array}{c}\text { Angle of line } \\
\text { Voltage }\left(V_{\mathrm{a}}\right)\end{array}$} & $\begin{array}{c}0^{\circ} \\
\sim 60^{\circ}\end{array}$ & $\begin{array}{c}60^{\circ} \\
\sim 120^{\circ}\end{array}$ & $\begin{array}{c}120^{\circ} \\
\sim 180^{\circ}\end{array}$ & $\begin{array}{c}180^{\circ} \\
\sim 240^{\circ}\end{array}$ & $\begin{array}{c}240^{\circ} \\
\sim 300^{\circ}\end{array}$ & $\begin{array}{c}300^{\circ} \\
\sim 360^{\circ}\end{array}$ \\
\hline $\begin{array}{c}\text { Controlled } \\
\text { Currents }\end{array}$ & $I_{\mathrm{p}}$ & $I_{\mathrm{a}}$ & $-I_{\mathrm{b}}$ & $I_{\mathrm{b}}$ & $-I_{\mathrm{c}}$ & $I_{\mathrm{c}}$ & $-I_{\mathrm{a}}$ \\
\cline { 2 - 8 } & $I_{\mathrm{n}}$ & $I_{\mathrm{c}}$ & $-I_{\mathrm{c}}$ & $I_{\mathrm{a}}$ & $-I_{\mathrm{a}}$ & $I_{\mathrm{b}}$ & $-I_{\mathrm{b}}$ \\
\hline \multirow{2}{*}{$\begin{array}{c}\text { Fixed } \\
\text { Switches }\end{array}$} & ON & $S_{b n}$ & $S_{a p}$ & $S_{c n}$ & $S_{b p}$ & $S_{a n}$ & $S_{c p}$ \\
\cline { 2 - 8 } & OFF & $S_{b p}$ & $S_{a n}$ & $S_{c p}$ & $S_{b n}$ & $S_{a p}$ & $S_{c n}$ \\
\hline
\end{tabular}

* The definitions of the symbols are the same as in Fig.1.

With the circuit in Fig.1 (b) operating according to the rotation sequence given in Table I and the control core equation (1) for APF, the control goal shown in equation (3) can be realized, which means that the duty ratio $d_{\mathrm{p}}$ and $d_{\mathrm{n}}$ are controlled by the selected phase currents and the DC bus voltage error so that the line currents are in-phase with the line voltages; therefore, unity power factor and low THD are achieved.

$$
V_{m} \cdot\left[\begin{array}{l}
1-d_{p} \\
1-d_{n}
\end{array}\right]=R_{s} \cdot\left[\begin{array}{ll}
2 & 1 \\
1 & 2
\end{array}\right]\left[\begin{array}{c}
I_{p} \\
I_{n}
\end{array}\right]
$$

and $V_{\mathrm{m}}$ defined as,

$$
V_{m}=R_{s} \cdot \frac{E}{R_{\mathrm{e}}}
$$

where, $d_{\mathrm{p}}$ and $d_{\mathrm{n}}$ are the duty ratios of the switches and $R_{\mathrm{s}}$ is current sensing resistance.

$$
\left[\begin{array}{l}
V_{a} \\
V_{b} \\
V_{c}
\end{array}\right]=R_{e} \cdot\left[\begin{array}{c}
I_{a} \\
I_{b} \\
I_{c}
\end{array}\right]
$$

where, $R_{\mathrm{e}}$ is the emulated resistance that reflects the real power of the load.

Equation (3) is the control goal of OCC-APF, i.e. the line currents are sinusoidal and in-phase with the line voltages, since the APF cancels the harmonic components generated by the nonlinear load. 


\section{DYNAMICAL ANALYSIS OF OCC-APF}

\section{A. Poincare mapping analysis for OCC-APF}

The OCC-APF is a large signal nonlinear system. Using the Poincare mapping technique ${ }^{[10]}$, the OCC modulation is convergent when the condition given in equation (4) is satisfied.

$$
m_{c} \geq \frac{m_{2}-m_{1}}{2}
$$

For the control circuit shown in Fig. 2, $m_{1}$ and $m_{2}$ are the rising and falling slope of the current $\left(\mathrm{R}_{\mathrm{s}}\left(2 i_{\mathrm{p}}+i_{\mathrm{n}}\right)\right.$, or $\mathrm{R}_{\mathrm{s}}\left(2 i_{\mathrm{n}}+\right.$ $\left.i_{\mathrm{p}}\right)$ ) respectively; $m_{\mathrm{c}}$ is the equivalent slope generated by the integrator with reset.

For APF operation, the currents have the relationship of

$$
\left[\begin{array}{c}
I_{a} \\
I_{b} \\
I_{c}
\end{array}\right]=\left[\begin{array}{l}
I_{L d-a} \\
I_{L d-b} \\
I_{L d-c}
\end{array}\right]+\left[\begin{array}{c}
I_{a p f-a} \\
I_{a p f-b} \\
I_{a p f-c}
\end{array}\right]
$$

where the first term in the right side of equation (5) is the load current vector, while the second one is the APF current vector.

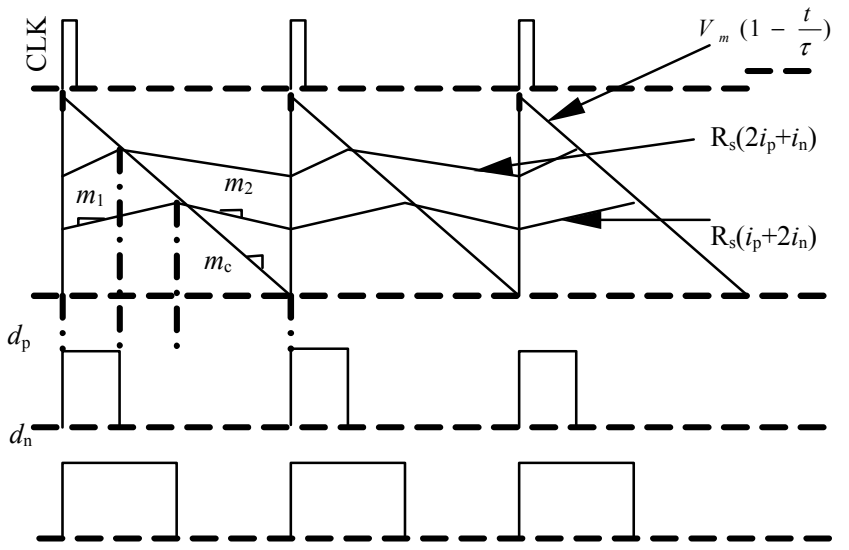

Fig.2 Operate waveforms of the OCC controller

Since the switching frequency of the APF is much higher than the one of the load current, the ripple of the control signals $\mathrm{R}_{\mathrm{s}}\left(2 i_{\mathrm{p}}+i_{\mathrm{n}}\right)$ and $\mathrm{R}_{\mathrm{s}}\left(i_{\mathrm{p}}+2 i_{\mathrm{n}}\right)$ in Fig. 2 is determined by the switching actions of the APF, i.e. the slopes $m_{1}$ and $m_{2}$ can be calculated from the APF branch only, which is verified by simulation.

Table II calculates the current slopes of $i_{\mathrm{a}}$ and $i_{\mathrm{c}}$, and therefore their linear combinations in region I $\left(0 \sim 60^{\circ}\right)$ and different switching states.

TABLE.II

Equivalents And CurRent Slew RATE OF $i_{p} \& i_{n}$ In Region I ${ }^{*}$

\begin{tabular}{|c|c|c|c|c|c|}
\hline $\begin{array}{c}\text { II } \\
S_{\text {an }}, S_{\mathrm{cn}} \\
\mathrm{OFF}, \mathrm{ON}\end{array}$ & 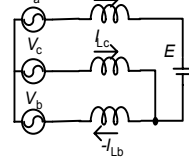 & $\frac{V_{a}-2 E / 3}{L_{f}}$ & $\frac{V_{c}+E / 3}{L_{f}}$ & $-\frac{E-V_{a b}}{L_{f}}$ & $\frac{V_{c b}}{L_{f}}$ \\
\hline $\begin{array}{c}\text { III } \\
S_{\text {an }}, S_{\mathrm{cn}} \\
\text { ON,OFF }\end{array}$ & 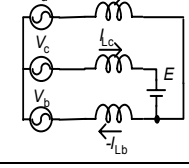 & $\frac{V_{a}+E / 3}{L_{f}}$ & $\frac{V_{c}-2 E / 3}{L_{f}}$ & $\frac{V_{a b}}{L_{f}}$ & $\frac{E-V_{c b}}{L_{f}}$ \\
\hline $\begin{array}{c}\text { IV } \\
S_{\text {an }}, S_{\mathrm{cn}} \\
\text { OFF,OFF }\end{array}$ & 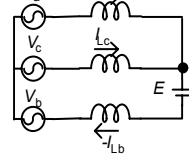 & $\frac{V_{a}-E / 3}{L_{f}}$ & $\frac{V_{c}-E / 3}{L_{f}}$ & $-\frac{E-V_{a b}}{L_{f}}$ & $\frac{E-V_{c b}}{L_{f}}$ \\
\hline
\end{tabular}

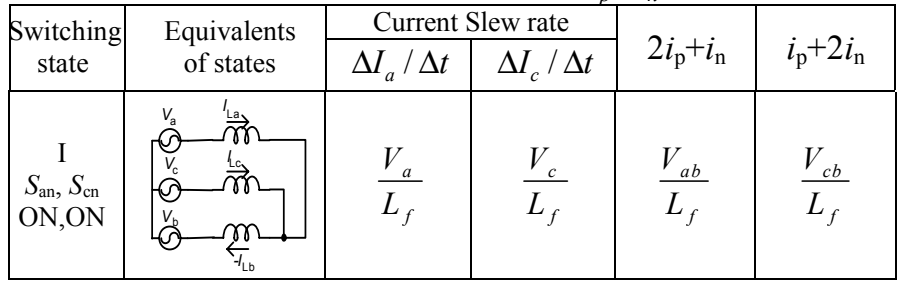

where, $V_{\mathrm{ab}}$ and $V_{\mathrm{cb}}$ are the line-line voltage of phases $\mathrm{A}$ and $\mathrm{C}$ to phase $\mathrm{B}$ respectively; $L_{f}$ is the inductance of the switching filter.

In Table II, only two switching sequences are possible-I, II, IV or I, III, IV, therefore, the slopes of $\mathrm{R}_{\mathrm{s}}\left(2 i_{\mathrm{p}}+i_{\mathrm{n}}\right)$ are as follows,

$$
m_{1}=\frac{R_{s} \cdot V_{a b}}{L_{f}} ; m_{2}=\frac{R_{s}\left(E-V_{a b}\right)}{L_{f}}
$$

Combination equation (4) and (6) yields the local stability condition

$$
V_{m} \geq \frac{R_{s} \cdot\left(E-2 V_{a b}\right)}{2 L_{f}}
$$

Using $V_{a b}=\sqrt{6} V_{a-r m s} \cdot \cos \left(\omega t-60^{\circ}\right)\left(\omega t=0^{\circ} \sim 60^{\circ}\right)$, the worst case of equation (7) occurs when $V_{a b}$ reaches the minimum and light load, since $V_{\mathrm{m}}$ reflects the load level referring to equation (2). It should be note that the result which is derived from $\mathrm{R}_{\mathrm{s}}\left(i_{\mathrm{p}}+2 i_{\mathrm{n}}\right)$ and/or other regions is essentially the same as it shown in equation (7). It is because of the symmetry of the three-phase voltage and the rotational regions. From equation (7), it can be concluded,

- Equation (7) shows the sufficient condition for global convergence of the OCC algorithm. Often, it is too stringent and unnecessary for circuit parameter selection. For example, larger inductance $L_{f}$ and small current sensor resistance $R_{\mathrm{s}}$ are helpful to keep the OCC-APF unconditionally stable; however, the maximal inductance $L_{f}$ and minimal resistance $R_{\mathrm{s}}$ are rstricted by other factors. In addition, the DC bus voltage $E$ must be large enough to keep the system works in Boost mode ${ }^{[4]}$, but if too high, it will make the system locally unstable.

- The OCC-APF can function stably even when equation (7) is only satisfied partially. Since $V_{a b}=\sqrt{3} V_{a-p k} \cdot \cos \left(\omega t-60^{\circ}\right)$ in a region of $0^{\circ} \sim 60^{\circ}, V_{\mathrm{ab}}$ varies between $\mathrm{V}_{\text {ab-peak }} / 2$ and $\mathrm{V}_{\text {ab-peak }}$, therefore, equation is always satisfied when $V_{\mathrm{ab}}$ approach its high end of the region if $E<2 \mathrm{~V}_{\text {ab-peak }}$ is designed. Suppose, equation (7) is not satisfied when $V_{\mathrm{ab}}$ is at its low end of the region, the in-convergence will be limited locally, i.e. the current will not grow unboundedly before the convergence condition is caught again. In light of the above analysis, 
it is safe to say that global stability for OCC-APF is guaranteed when $\mathrm{E}<2 \mathrm{~V}_{\text {ab-peak, }}$ which gives a necessary condition for stability and a much greater freedom to the circuit parameter selection.

\section{$B$. Large signal perturbations of the $O C C-A P F$}

Following time domain simulation results show verification the necessary condition.

- Changes of operation state, e.g. start and/or stop of the circuit;

- Fast load change, e.g. load power varies in step;

- Characteristic transient, e.g. the current transient between the phases of three-phase rectifier with inductive choke.

- Large random perturbations from fault or environment.

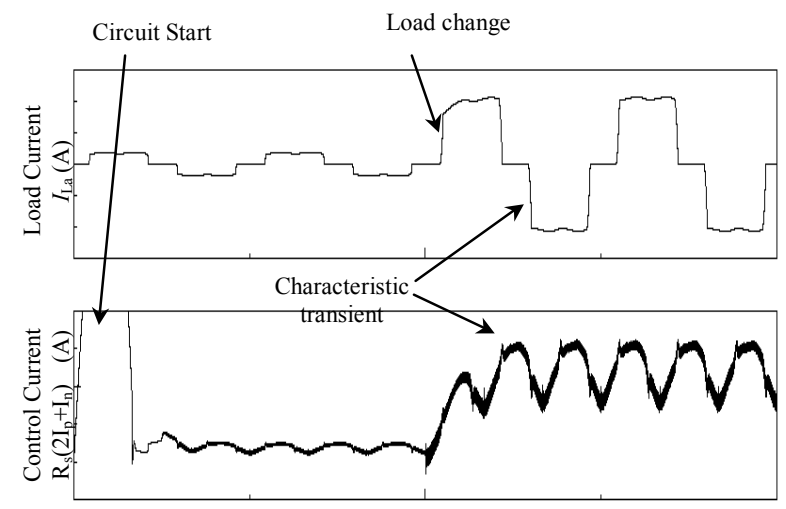

Carrier amplitude

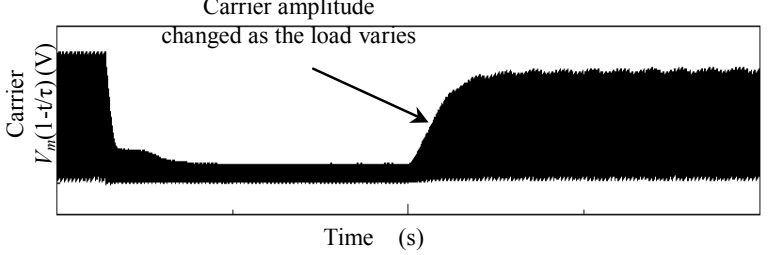

Fig.3 Simulation for some large signal perturbations of OCC APF

As a practical example, the first three large perturbations are simulated as shown in Fig.3. Referring to Fig.1 (b), the signals applied to the comparators should have proper values so that the duty ratios $d_{\mathrm{p}}$ and $d_{\mathrm{n}}$ locate in a practical range, e.g. $d_{\max }=0.9$ and $d_{\min }=0.1$ are the maximal and minimal duty ratios respectively. Here one of the two signals is investigated in one of the six regions (e.g. region I). The result is valid for all regions due to the symmetric operation.

$$
V_{m}\left(1-d_{\max }\right) \leq R_{s} \cdot\left(2 I_{p}+I_{n}\right) \leq V_{m}\left(1-d_{\text {min }}\right)
$$

The physical meaning of this equation is that the values of $R_{\mathrm{s}}\left(2 I_{\mathrm{p}}+I_{\mathrm{n}}\right)$ must locate within the envelop of $V_{\mathrm{m}}\left(d_{\min } \sim d_{\max }\right)$. In OCC-APF, $V_{\mathrm{m}}$ is adjusted according to the power level with a PI controller according to equation (2) and the variable amplitude carrier is implemented as shown in Fig.3

Any perturbations adding to signal $R_{\mathrm{s}}\left(2 I_{\mathrm{p}}+I_{\mathrm{n}}\right)$ have the equivalent effect to change the relative position of signal $R_{\mathrm{s}}\left(2 I_{\mathrm{p}}+I_{\mathrm{n}}\right)$ to the carrier. There are four common types in practice: I, II, III and IV, which are positive or negative perturbation adding to the rising or falling edges respectively, as shown in Fig.4. Maximal duty ratio must be used to prevent the leg's short-through. This is because the perturbation of type-III/-IV may cause the comparator never turning around during the whole switching cycle of this or next one(s).

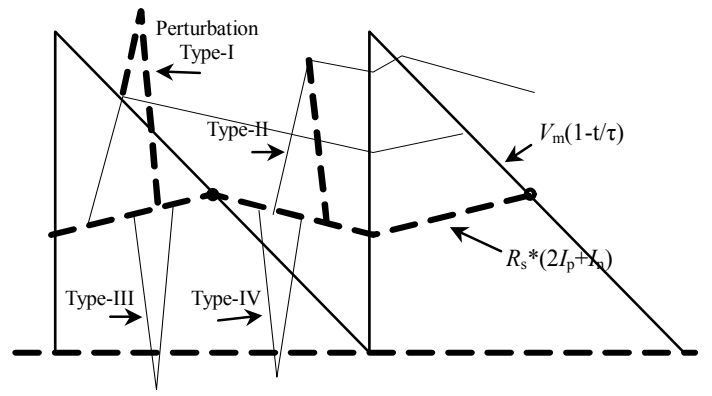

Fig.4 Large signal perturbations to the OCC controller

\section{Transient tracking of the OCC APF}

Although OCC technology has faster dynamical response compared with the ones with traditional PWM, it is still a challenge for OCC-APF to track the extreme fast current transient since the tracking speed is not only determined by the control but also by the main circuit, for example, the inductance $L_{f}$ of the switching filter.

The characteristic load current transient caused by the commutation of the phases of a three-phase rectifier with inductive choke is shown in Fig.3. This transient is one of the large signal perturbations to the control system that mentioned above; furthermore, it degrades the steady-state performance of the APF if it cannot be compensated. Only the main circuit factors are discussed in this section.

In the point of view of switching ripple filtering, the larger inductance $L_{f}$, and the smoother output current. However, from Table II, it can be seen that the current slew rate in the APF branch is always in inverse proportion to the filter inductance. For the reason that the current slew rate is proportional to the nonlinear load power, therefore, in the heavy power condition, slew rate is the dominated factor to determine the filter inductance, i.e. small value of $L_{f}$ is preferred.

It is obvious that factors of filtering and providing fast transient compensation are conflicting, which is difficult to tradeoff when the load power varies in a large range, e.g. $10 \sim 100 \%$ of the power rating. To solve this problem, an adaptive inductance $L_{f}$ is introduced in this paper, which changes with the power level along with curve shown in Fig.5(a), where $I_{\mathrm{La}} I_{\mathrm{a}} I_{\mathrm{Lf}}$ are the phase-A current of load, line and the APF respectively.

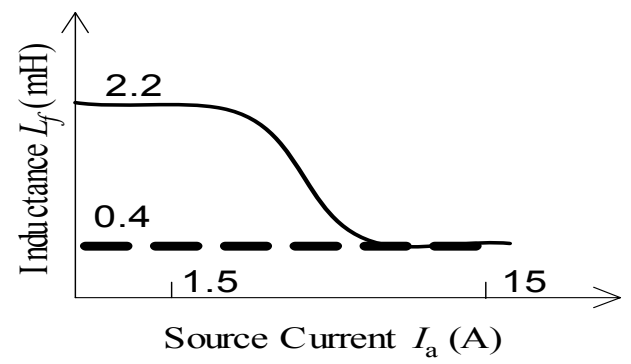

(a) The inductance of the filter adaptive with the load current 


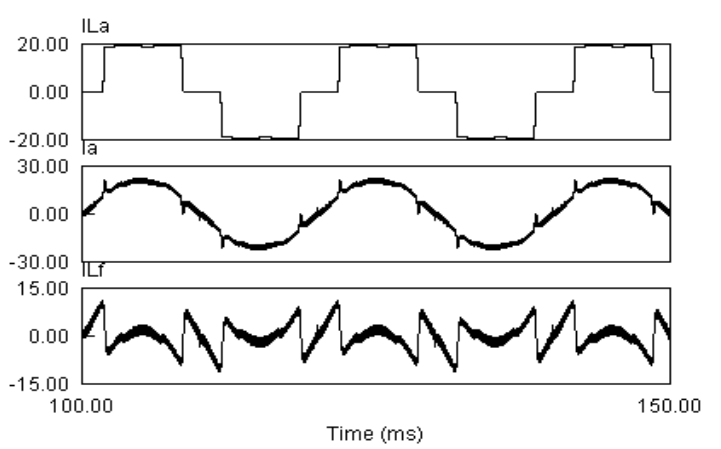

(b) Waveforms in heavy power condition $(5.6 \mathrm{~kW})$

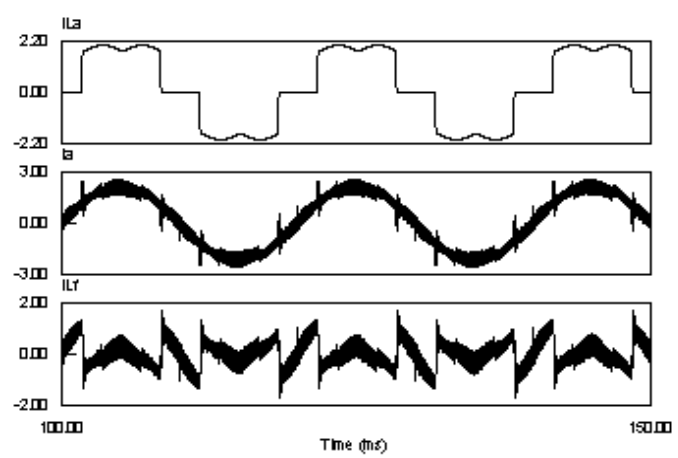

(c) Waveforms in light power condition $(0.54 \mathrm{~kW})$

Fig.5 Adaptive filter inductance and its effects to the OCC-APF

Fig.5 (b) and (c) show the simulation waveforms of the designed OCC APF in heavy load $(5.6 \mathrm{~kW})$ and light load $(0.54 \mathrm{~kW})$ conditions respectively with the adaptive filter inductance adopted. It also shows that the waveforms in both light and heavy conditions have an acceptable switching ripple and good transient current compensation.

\section{THREE-PHASE 5kW OCC-APF PROTOTYPE}

\section{AND EXPERIMENTS}

A $5 \mathrm{~kW}$ pre-industrial prototype of a three-phase active power filter (APF) with One-Cycle Control (OCC) and vector operation was built as shown in Fig. 6. The prototype has house keeping power supplies, over-voltage, over-current and over-heat protections, stop-start preset sequence, full isolation, which are usual required in industrial applications.

The experiment conditions and parameters are:

Power line:

$120 \mathrm{Vrms} / 60 \mathrm{~Hz} / 3$-phase

Output power: $\quad 5.0 \mathrm{~kW}$ (varies from $10 \%$ to $110 \%$ )

DC bus voltage/ capacitance: $\quad 365 V_{\mathrm{dc}} / 960 \mathrm{uF}$

Sensor resistor (Loop gain): $\quad R_{\mathrm{s}}=0.075 \Omega$

Sensor bandwidth:

$12.5 \mathrm{kHz}$

Switching frequency:

$f_{\mathrm{s}}=25 \mathrm{kHz}$

Switching filter (adjustable):

$0.4 \sim 2.2 \mathrm{mH}$

The steady-state waveforms of the load, the power line, and the OCC-APF with vector operation are shown in Fig.7 (a), (b), (c) respectively.

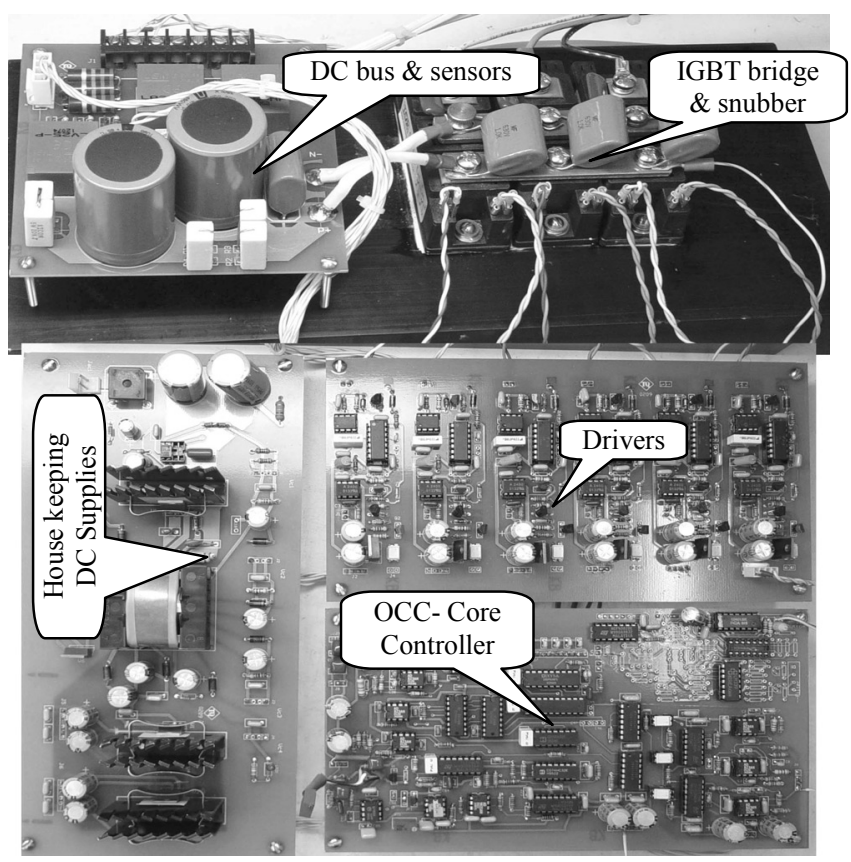

Fig.6 The $5 \mathrm{~kW}$ pre-industrial prototype of the OCC-APF with vector operation

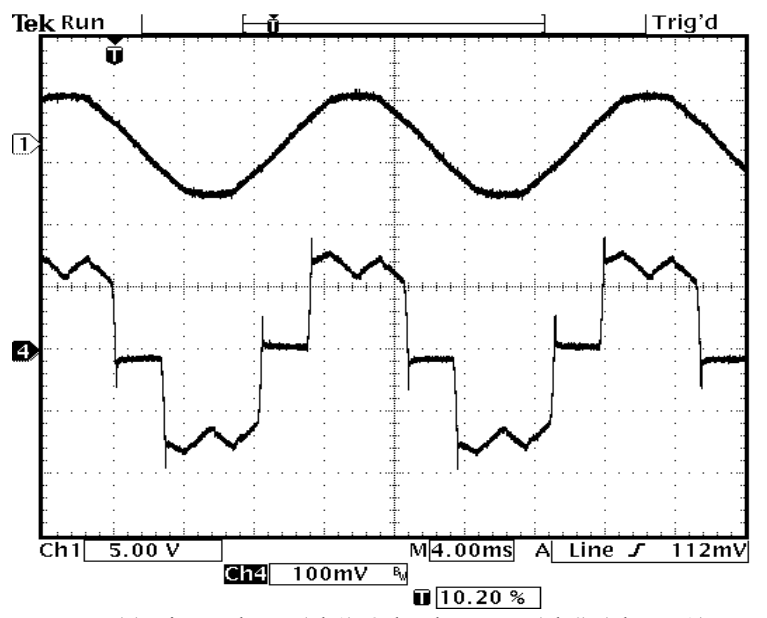

(a) Line voltage (ch1) \& load current (ch4) (phase-A)

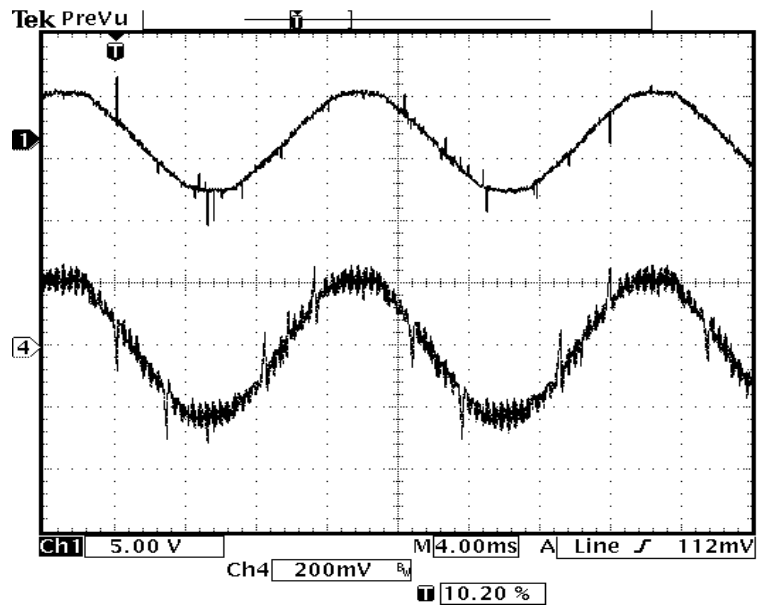

(b) Line voltage (ch1) and line current (ch4) (phase-A) 


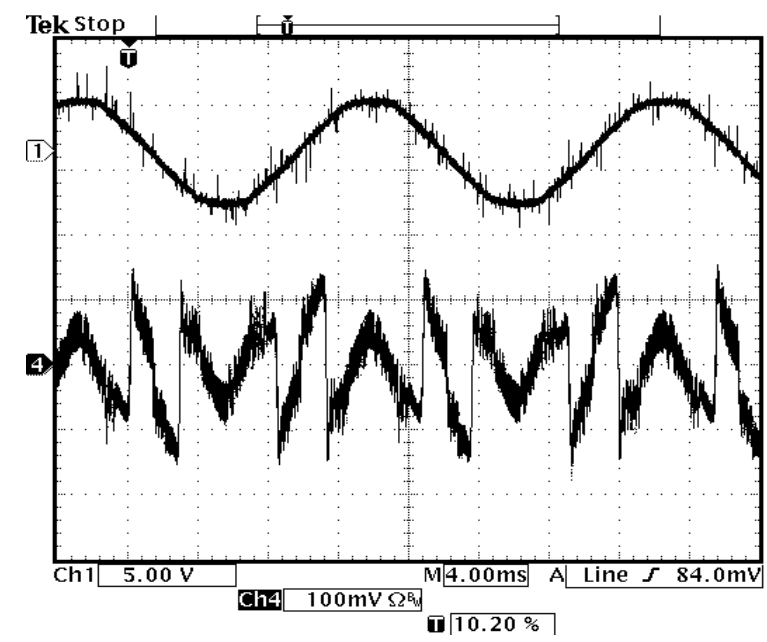

(c) Line voltage (ch1) \& OCC-APF current (ch4) (phase-A) Fig.7 Steady-state experimental waveforms

The spectrum of the phase current is obtained using the FFT analyzer of the TDS3202 oscilloscope. The data of the current in frequency domain is given in Table. III

TABLE. III

EXPERIMENTAL CURRENT COMPONENTS OF OCC-APF (phase A)

\begin{tabular}{|c|c|c|c|}
\hline THD & $\begin{array}{c}\text { Line Current } \\
\left(I_{\mathrm{n}} / I_{1}\right)\end{array}$ & $\begin{array}{c}\text { APF } \\
\text { Current } \\
\left(I_{\mathrm{n}} / I_{\mathrm{rms}}\right)\end{array}$ & $\begin{array}{c}\text { Load Current } \\
\left(I_{\mathrm{n}} / I_{1}\right)\end{array}$ \\
\hline $1^{\text {th }}$ & $100 \%$ & - & $\sim 30 \%$ \\
\hline $5^{\text {th }}$ & $2.6 \%$ & $11 \%$ & $100 \%$ \\
\hline $7^{\text {th }}$ & $2.3 \%$ & $39 \%$ & $25.4 \%$ \\
\hline $11^{\text {th }}$ & $2.7 \%$ & $18 \%$ & $9.6 \%$ \\
\hline $13^{\text {th }}$ & $2.8 \%$ & $15 \%$ & $7.9 \%$ \\
\hline $17^{\text {th }}$ & 0 & 0 & $6.2 \%$ \\
\hline $19^{\text {th }}$ & 0 & 0 & $4.5 \%$ \\
\hline $23^{\text {rd }}$ & 0 & 0 & $4 \%$ \\
\hline
\end{tabular}

Figure 7 and Table.III demonstrated that the designed OCC-APF improve the current THD caused by the nonlinear load from about $30 \%$ to about $5 \%$. i.e. the APF compensates the harmonics so that the system draws approximate pure sinusoidal current from the power line; while the APF generate almost the all harmonics produced by the nonlinear load, and a very small fundamental component exist to keep the DC bus voltage constant.

To demonstrate the dynamical performance of the prototype, both the startup and load variation transients were investigated.

Figure 8 shows the dynamical waveforms when the OCC APF started. The response of the currents of the line and APF branches are shown in Fig.8 (a) and (b) respectively, while the DC bus voltage is shown in Fig.8(c). It can be seen that there is no dangerous overshot occurs and the response speed is proper after the APF is started.

Figure 9 shows the dynamical waveforms when the nonlinear load power changed from $50 \%$ to $100 \%$ of $5 \mathrm{~kW}$ in step. The response of the currents in the load, the line and the
APF branches are shown in Fig.9(a), (b), and (c) respectively. It can be seen that transient is smooth, fast and stable.

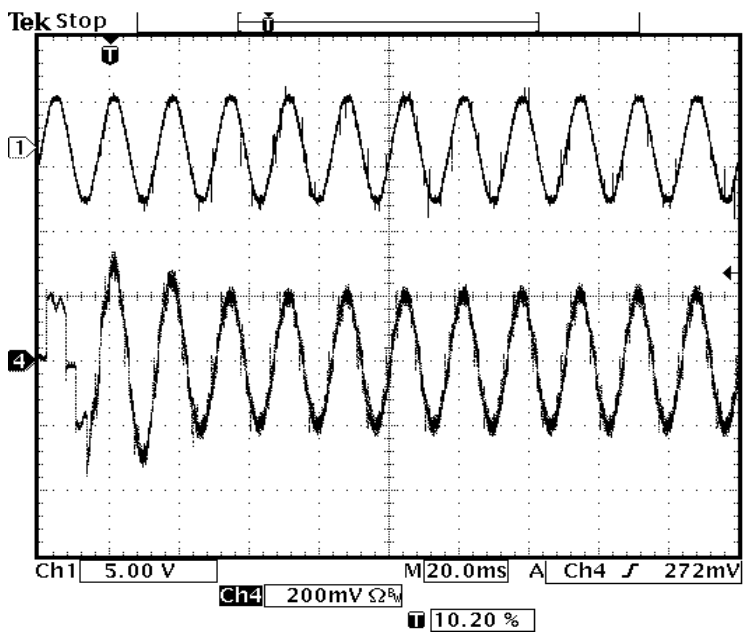

(a) Line voltage (ch1) and current (ch4) (Phase-A)

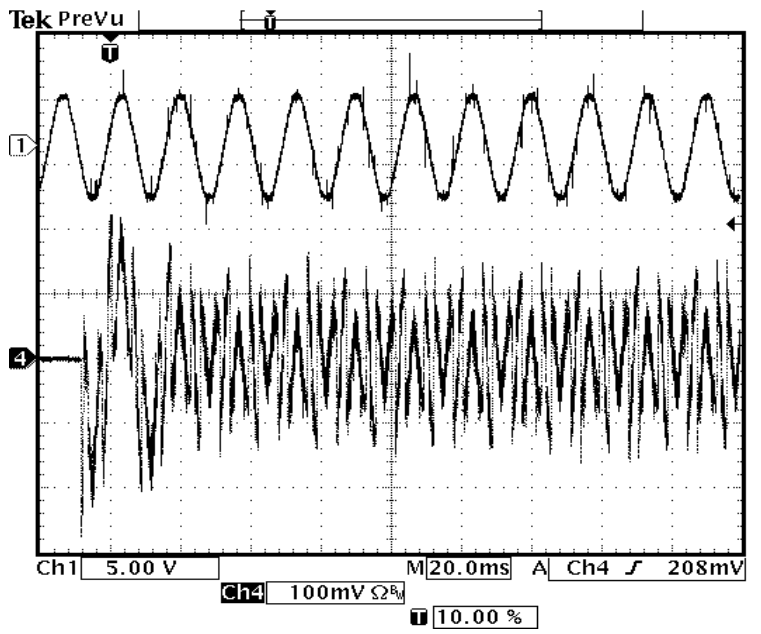

(b) Line voltage (ch1) and OCC-APF current (ch4) (Phase-A)

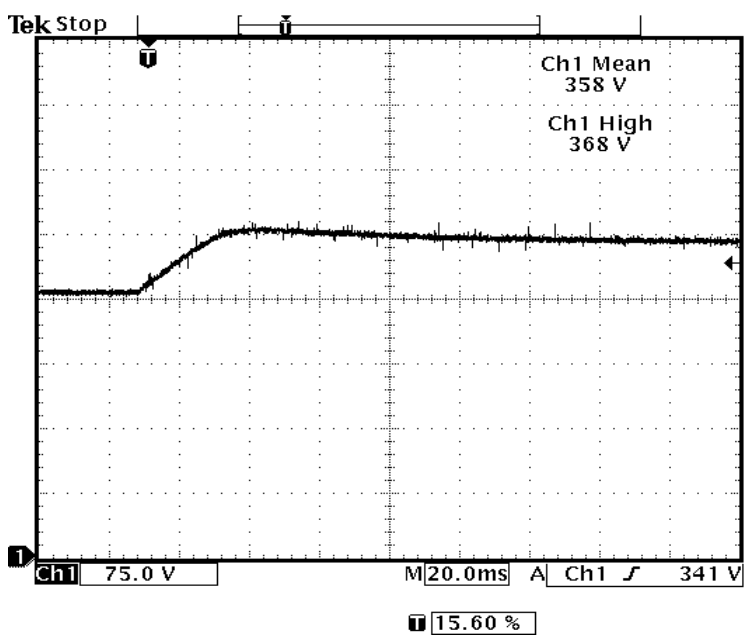

(c) DC bus voltage

Fig.8 Dynamical waveforms of OCC-APF when it is started 


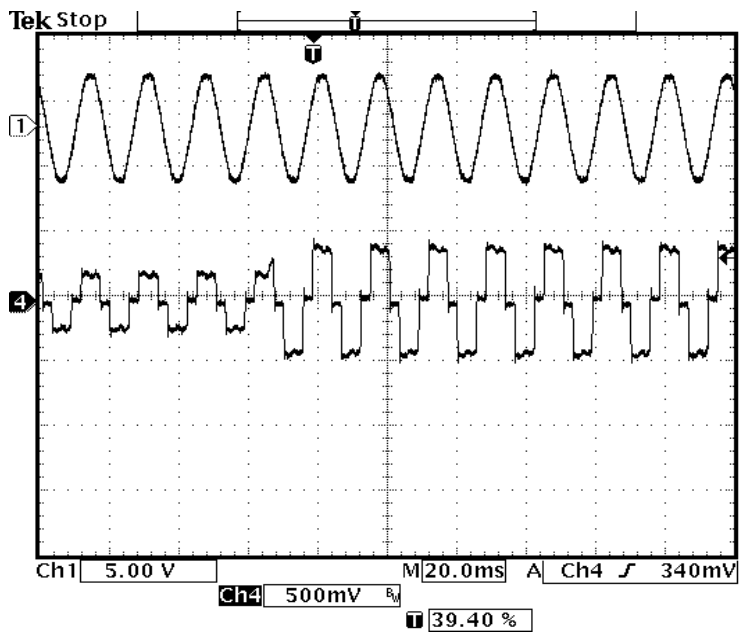

(a) Line voltage (ch1) \& load current (ch4) (Phase-A)

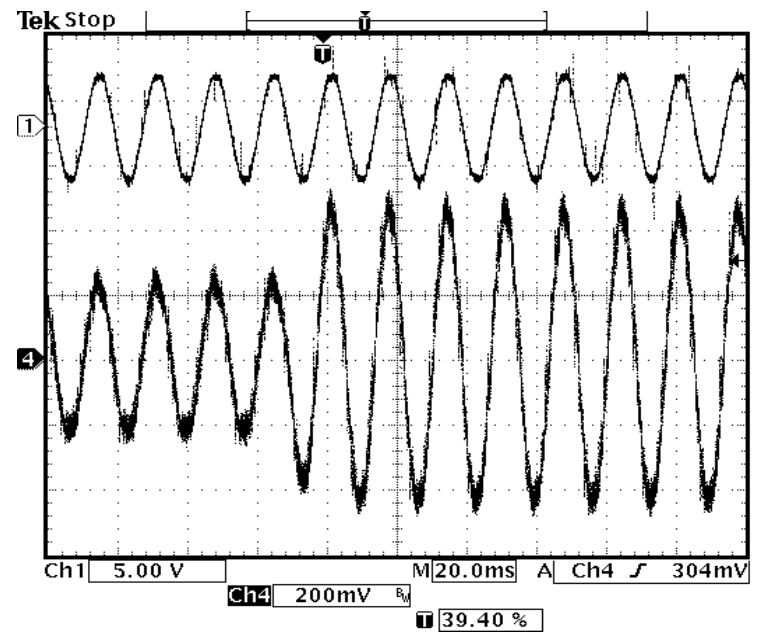

(b) Line voltage (ch1) and current (ch4) (Phase-A)

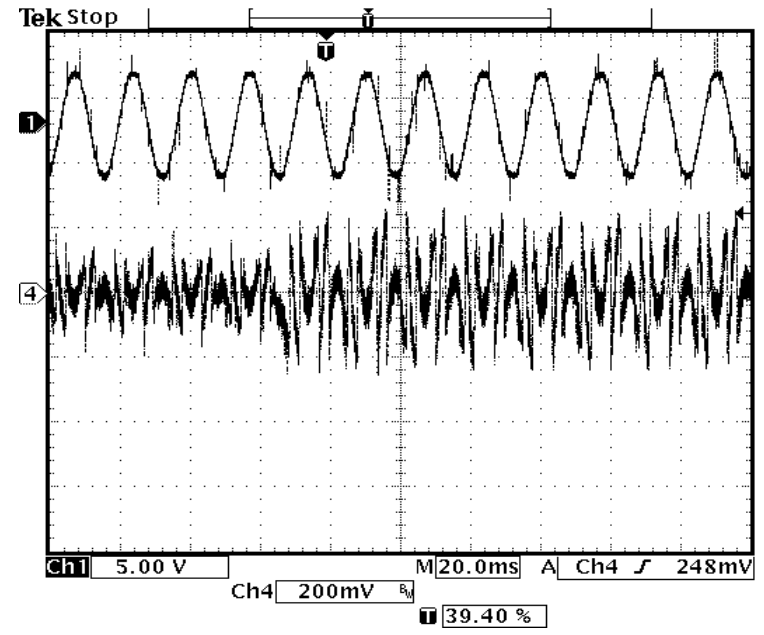

(c) Line voltage (ch1) \& OCC-APF current (ch4) (Phase-A) Fig.9 Dynamical waveforms of OCC-APF as load power changes from $50 \%$ to $100 \%$ in step

From Fig.7 Fig.9, the characteristic transient of the load is suppressed to acceptable level with OCC control and the adaptive inductance $L_{f}$ of the filter. In summary, the OCC-APF has,

- Excellent steady-state performance of harmonics suppression.

- No overshot occurs in transient states including the circuit start and power changed in step.

- Fast dynamic current tracking ability.

- Stable and reliable operation.

\section{V.CONCLUSION}

One-Cycle Controlled Active Power Filters (OCC-APF) with vector operation reported by literature [4] is a promising technology due to its universality, simplicity, fixed switching frequency, and robust performance.

This paper focuses on the study of the performance both steady-state and dynamics. The stability condition for the OCC-APF is first derived in this paper. Analysis of some typical large signal perturbations and the tracking for fast transient are also investigated from the control circuit and inductor design point of view. Some design rules and guidelines are provided to keep the system stable and with high performance. Experimental results based on a three-phase $5 \mathrm{~kW}$ pre-industrial APF prototype verified that the OCC-APF achieves excellent performance in both steady-state and dynamical operations.

\section{REFERENCES}

[1] K. Smedley and S. Cuk, "One-Cycle Control of Switching Converters," 22nd Annual IEEE Power Electronics Specialists Conference (Cat. No.91CH3008-0), Cambridge, MA, 1991. pp. 888-96.

[2] Smedley, K.M.; Zhou, L.; Qiao, C, Unified constant-frequency integration control of active power filters-steady-state and dynamics, Power Electronics, IEEE Transactions on , Volume: 16 Issue: 3 , May 2001,Page(s): $428-436$

[3] Smedley, K.M.; Cuk, S.,Dynamics of one-cycle controlled Cuk converters, Power Electronics, IEEE Transactions on, Volume: 10 Issue: 6, Nov. 1995, Page(s): $634-639$

[4] C. Qiao, T. Jin, and K. Smedley, Unified Constant-frequency Integration Control of Three-phase Active-Power-Filter with Vector Operationt, IEEE Power Electronics Specialists Conference, June 2001

[5] Chongming Qiao; Smedley, K.M.; Unified constant-frequency integration control of three-phase standard bridge boost rectifiers with power-factor correction; Industrial Electronics, IEEE Transactions on , Volume: 50 Issue: 1 , Feb. 2003,Page(s): 100 -107

[6] Chongming Qiao; Smedley, K.M.; Maddaleno, F., A comprehensive analysis and design of a single phase active power filter with unified constant-frequency integration control, Power Electronics Specialists Conference, 2001. PESC. 2001 IEEE 32nd Annual, Volume: 3 , 17-21 June 2001,Page(s): 1619 -1625 vol. 3

[7] Chongming Qiao; Smedley, K.M., A general three-phase PFC controller for rectifiers with a parallel-connected dual boost topology, Power Electronics, IEEE Transactions on, Volume: 17 Issue: 6, Nov 2002

[8] Fujita, H.; Akagi, H, A practical approach to harmonic compensation in power systems-series connection of passive and active filters,Industry Applications, IEEE Transactions on , Volume: 27 Issue: 6 , Nov/Dec 1991 Page(s): $1020-1025$.

[9] F. Z. Peng and J. S. Lai, "Generalized instantaneous reactive power theory for three-phase power system," IEEE Trans. Instrum. Meas., vol.45, pp. 293-297, Feb. 1996

[10] K. Smedley, "Poincare stability analysis of switching converters with nonlinear control," IEEE Power Electronics Society Newsletter Vol14, No. 1, Jan, 2002. 